\title{
2
}

\section{The Value of the Humanities}

\section{Introduction}

What is the value of the humanities? This is a question that guides us throughout this report as we seek conceptual clarity and credibility for practices in digital humanities, knowledge exchange, globalisation, interdisciplinarity, infrastructure and public policy. In this chapter, however, we address the question head-on as we report on how humanities researchers themselves articulate the value of their work. This chapter reveals that humanists across the globe more often than not identify a social value to humanities research.

By way of our interviews and literature review, we have identified a bounded set of answers to the question of the value of humanities research. They are as follows:

Intrinsic value: humanities research has a value in and of itself. Even if it leads to other benefits (as listed below), it should also be pursued for its own sake.

Social value: the humanities benefit society in a number of ways. They help create tolerance and understanding between citizens, thereby leading to social cohesion. They aid decision-making, especially on the complex ethical issues that confront society as a whole. In addition, they can benefit society by challenging established positions (see also 'critical thinking' below).

Cultural heritage: the humanities enable citizens to understand, preserve and sometimes challenge their national heritage and culture.

Economic value: there are direct economic benefits from humanities research, for example in publishing, media, tourism and, of course, 
the training humanities scholars provide to their students, who go into the job market across a wide range of professions.

Contribution to other disciplines: humanities research feeds into other fields, most obviously the social sciences, but also into medicine, computer science and engineering/design.

Innovation: the humanities deal with questions of motivation, organisation and action, which are essential components of creativity and entrepreneurship, and so the humanities promote a culture of innovation.

Critical thinking: it is of the essence of the humanities to develop critical thinking. This is epitomised by the Socratic tradition in philosophy, but by no means confined to that discipline.

Personal and spiritual development: humanities research can enhance one's personal and spiritual wellbeing through the study of different texts and traditions - religious, philosophical or spiritual.

Aesthetic appreciation: literary research, art history and musicology promote aesthetic discrimination, enhancing the appreciation and enjoyment of artistic works.

We argue that this list represents a plausible taxonomy of the most prominent attempts to articulate the value of the humanities around the world. It is, of course, possible to classify the value of the humanities at different levels of generality. At the very general end of the spectrum one hears claims such as 'the humanities make us human'. At the other extreme one might take examples from a particular discipline that have led to some benefit or other, e.g. philosophical research in bioethics. But we think that dividing the terrain at an intermediate level of specificity (as above) will bring clarity to a topic often marked by excessive abstraction and hyperbole.

Our purpose is not to advocate any of the values in particular; it is to describe and analyse them and to offer some critical reflections. We also wish to show how support for these values is weighted differently around the world.

The list is based on research from a number of different sources:

- A literature review of national reports, opinion pieces in the media, books (scholarly and popular) and articles in journals and edited books

- Interviews with 89 humanities researchers worldwide

- Workshops with scholars from several countries, especially from East Asia, Russia and Latin America. 
In the interviews, all respondents were asked the following questions:

Why fund research in the humanities? If you had to give a succinct answer to this question, what would it be? How would you articulate the value of humanities research to an impatient and potentially hostile audience?

We phrased the question in this way to avoid taxing the patience of our interviewees with a completely open-ended question about the value of the humanities. In effect, we were asking as much about the rhetoric of justification as the justification itself. Nonetheless, the responses to this question have been a very useful guide towards understanding people's own opinions on the value of the humanities.

In the first 45 interviews, we confined ourselves to this question. However, as we gathered more information on the issue, we decided to add an extra component to this section of the questionnaire. Since we had by this point a reasonably clear classification of the different values that humanities research might be thought to have, we decided to present them in a list to respondents and ask for their reactions. This is how we phrased the additional request:

Here are some ways of expressing the value of humanities research:

(a) Intrinsic value

(b) Informing social policy

(c) Understanding cultural heritage

(d) Promoting economic value

(e) Contributing to other academic disciplines (e.g. in the natural or social sciences)

(f) Feeding through to undergraduate education

(g) Promoting critical thinking and innovation

Which of these in your own view is (or are) the most important? Which of these is considered most important in your country/region?

This allowed us to distinguish what the respondents themselves thought about the value of the humanities from the dominant discourse in their country. In the analysis below, we have highlighted the extra information that came out of the revised question.

Reports, books and articles allow their authors to articulate a particular value in detail. But there is a risk that such pieces tell us more 
about the individual authors than about frequently held attitudes in the regions from which they come. By complementing these sources with our interview results, we hope to provide a somewhat broader perspective, although the risk of idiosyncrasy remains. In addition, the HWR workshops have allowed us to talk around the interview results and the literature review to deepen our understanding of the different types of value and the distinctions and tensions between them.

All the items on the list feature somewhere in the interviews and, although the list is not a completely exhaustive account of everything said in those interviews, we have tried not to omit any significant categories of value. We hope that this list does indeed represent the approaches that are dominant in different regions of the world.

The values overlap in different ways. For instance, many would see social value and cultural heritage as continuous with each other. Or, as we have already indicated, one of the social benefits of the humanities is critical thinking and innovation is often closely associated with economic and social value. But our task is first and foremost to report on the different values commonly attributed to humanities research. It is certainly useful, for the sake of clarity, to start with some distinct categories, even if they eventually become blurred in the broader discussions that we hope to stimulate. Another point to bear in mind is that these values can come into conflict with each other in specific instances: pursuing intellectual curiosity because of intrinsic value may conflict with economic value (though this need not necessarily be the case); critical thinking and innovation may not always be conducive to social cohesion. But our task is not to reconcile these tensions, but to articulate the different values espoused around the world.

One question we had to confront was whether to include undergraduate education as a distinct benefit of humanities research. After some reflection, and discussion in the workshops, we have decided against this for the following reason. As well as the distinction between the different kinds of value that humanities research may have, one can distinguish different ways in which humanities researchers might deliver such benefits: by appearing on TV; by writing popular books; by working with museums and galleries to create content for the general public (audio or written); by sitting on government committees to formulate policy or on ethics committees (e.g. in hospitals). These categories are precisely those to be discussed in Chapter 5 under the heading of 'translation'. But one of the most important ways of delivering these benefits is through undergraduate education. That is, the outcomes of humanities research typically filter down to undergraduate courses, which in turn may make 
their students better qualified for the workplace (economic value), better citizens (social value), better at critical thinking or appreciating works of art and so on. However, it would be a mistake to list education as a distinct value alongside the nine listed above since it is a distinct mode of delivery.

In Sections 1-9, we describe and analyse each of the values listed above more closely, adding in some critical remarks where appropriate. As already indicated, the sources for this work derive from the literature review, the interviews and the workshops. Sections 10-11 will focus directly on the interview results in more detail, first to illustrate how support for these values is distributed in different regions of the world, and second to highlight respondents' views on the very idea of 'justifying' the humanities.

\section{Intrinsic value}

\section{Analysis}

Any academic discipline can be defended on the grounds of intrinsic interest. That pursuing knowledge and understanding is valuable for its own sake and does not actually require some further goal in order to be of value (of course, researchers who are driven by intrinsic value may have additional and more personal motivations, which may explain their particular choices of field and topic). In the case of the humanities, the intrinsic value argument is that, as human beings, we ought to have an interest in our history, culture, ideas, languages and so on. As part of our interviews, we found this approach widespread in almost all regions. It can also be found in discussions of the humanities, one of its major proponents in the US being Stanley Fish, ${ }^{1}$ but it is certainly not a new idea. Again in the US, it has featured prominently in discussions of the liberal arts, when their advocates claim that undergraduates (no less than their professors) should study these subjects just for their own sake. The nineteenth century Harvard professor Charles William Eliot, who was one of the most important figures in the development of the liberal arts in the US, talked of 'the enthusiastic study of certain subjects for the love of them without any ulterior object'. ${ }^{2}$

One of our interview respondents made the point quite succinctly:

NA8: To me the justification for humanities research is quite basic, quite fundamental. It extends human knowledge and human appreciation of language and literature and the arts. It is a good in and of itself. 
Three others, from quite different regions, made related points even more briefly (though with a hedonistic twist in one case):

As16: The humanities are just interesting!

ME2: The nicest thing about history is that it might be of no use. That's a definition of luxury.

R8: 'Why fund the research in the humanities?' Just because it's fun. And that's it.

\section{Intrinsic value and justification}

Intrinsic value may seem highly problematic as a way of defending the humanities, however much support it has among scholars themselves. ${ }^{3}$ It could invite charges of self-indulgence, especially from people outside academia and in times of economic hardship. So, if one is concerned with defending the humanities, the temptation might be to abandon appeals to intrinsic value and resort immediately to arguments that appeal to the social or economic benefits of the humanities (even if this goes against what we actually believe as scholars).

But perhaps this is too simplistic. The idea that the humanities have intrinsic value is by no means confined to academics. There are funding contexts in which the intrinsic value approach does have force, notably when dealing with philanthropic donors. ${ }^{4}$ Even in the public arena the intrinsic value approach should not be dismissed. At least in some countries, evidence from publishers and TV and radio outlets suggests that the broader public has a strong interest in subjects such as history, literature and archaeology. ${ }^{5}$ A successful defence will attempt to change the perception of the humanities from being a mere burden on the taxpayer to a set of disciplines whose subject matter already engages the interest of large swathes of the public. ${ }^{6}$ Interestingly, although the intrinsic value approach applies as much to the natural sciences as to the humanities, it may actually be easier to apply in the case of the humanities, as the subject matter is somewhat closer to people's concerns. This point came out of a few responses, as in the following from Europe:

E6:... there is a broad interest in the society at large in the subjects that are studied within the humanities, such as history, religion, literature, art, theatre, language, etc. Even if these are interests that most people pursue in their pastime and/or as concerned citizens, they are important in their own right, and we therefore need people who study these subjects professionally and in that capacity are able to transmit knowledge to the rest of society. 


\section{A hybrid approach}

It is also worth mentioning a hybrid approach to the value of the humanities, which combines instrumental and intrinsic elements (though it is ultimately instrumental in character). In discussing the economic and other benefits of the sciences, there is a well-known line of argument that one cannot always know in advance what research will yield benefits, whether technological, commercial or medical. So, the argument runs, the best course is to allow intellectual curiosity to run its course, to allow scientists to work as if they value research for its own sake, and then let the economic and other benefits fall out serendipitously. The same argument can be made for the humanities, especially in respect of certain items on the list such as social and economic values, innovation and the benefit the humanities may bring to other disciplines. If one is confined to what seems economically or socially useful, one may miss out on the most fruitful avenues of research. So, as in the sciences, it is best to embark on one's research with a non-instrumentalist mindset and to proceed as if one is pursuing it for its intrinsic value. However, this is still an instrumentalist approach, the ultimate value here is not intrinsic value but, psychologically, it embraces the intrinsic approach.

\section{Social value}

The social value of the humanities could be broken down into various kinds, perhaps the two most frequent being cohesion and decisionmaking.

\section{Social cohesion}

The humanities have been thought to promote social cohesion. One way is through undergraduate education, a point widely discussed in the commentary on US liberal arts, where the role of the humanities in enhancing our ability to communicate is central: by making people better able to articulate their viewpoints, they ease communication within society. Also, by equipping them to understand different viewpoints, they make citizens more tolerant of each other (a point that applies across national boundaries, of course, and so the humanities can be seen to be useful in an increasingly globalised world).

The link between the humanities and social cohesion can be clearly made for specific disciplines. History gives a sense of the past, especially of other people's pasts, which is vital for democratic citizens living together in an increasingly globalised world. Literature opens up our 
imaginative potential, as do the arts more generally, thus making us more sensitive to the attitudes and emotions of our fellow citizens. Religious studies help us understand different religious and spiritual traditions. Philosophy requires its practitioners to understand other viewpoints, even when they disagree with them. ${ }^{7}$ Although there are plenty of references to social value in the North American literature, it is by no means confined to that region. In South Africa, for example, it is part of the public discourse about the humanities. ${ }^{8}$

Here are some examples making this point, one from a Japanese respondent, two from the US and one from Latin America:

As1: [w]e need the understanding of the humanities, which restores human cooperation and partnership, more than economics or technology.

NA2: The humanities are what keep us human...: [i.e.] the abilities associated with reading, writing, thinking clearly and communicating with other people. If you can't relate with other human beings, what is any of this for?... People are losing touch with each other and it is, paradoxically, getting worse with social media. And the humanities are the secret to maintaining an appreciation for what makes human beings special.

NA12: A world without the humanities is one without value, meaning and a sense of shared community with each other.

LA10: [the] humanities are essential to overcome certain trends that are highly contrary to minimal social stability, e.g. xenophobia, racism, aggressive behaviour, addiction and fanaticism.

\section{Social decision-making}

Another aspect of the social value of the humanities concerns decision-making in politics, international relations, medicine, welfare; and with the use of new technologies societies have increasingly complex decisions to make. The humanities are, it is argued, indispensable here.

The level at which decisions need to be made varies. It could be a matter of individual citizens being equipped to contribute to public debate, to vote, or make decisions in their place of work. Humanities research can exert an influence, albeit sometimes indirectly, not only through undergraduate education, but also by dissemination through public media. But humanities researchers might also be enlisted to inform public policy directly. Whether or not this actually happens, 
and to what extent, is a question for later chapters. Here, we are merely pointing out that humanists tend to think that, in principle, their disciplines could make such a contribution.

One could illustrate the point in more specific terms by looking either at individual disciplines, or at areas of policy (e.g. health, environment or security). Where individual disciplines are concerned, one of the clearest ways in which philosophy can contribute to policy is through bioethics, on such issues as stem cell research and informed consent. There are also plenty of examples of the value of linguistics research, as in the understanding (and preservation) of minority languages, and sociolinguistic issues about differences of dialect and their relation to social status. ${ }^{9}$

If one wants to look at policy areas, a recent example concerns security in the US. In May 2011 the National Humanities Alliance and the Association of American Universities co-sponsored a meeting on Capitol Hill in Washington entitled Addressing National Security \& Other Global Challenges Through Cultural Understanding. ${ }^{10}$ Also, the EU Commission's Horizon 2020 Programme includes a call for research projects on 'Secure Societies'. Another good example is environmental policy, which can draw upon many different disciplines - history, archaeology, anthropology, philosophy, literature and theology.

Several of our interview respondents from different regions noted the importance of the humanities for social decision-making:

Af8: [The humanities'] results will help us to understand the context of social and economic phenomena and enable us to attempt to influence policy makers in their decisions.

ME1: The SSH help us to solve social problems. First we must understand human beings, only then can we help people control social phenomena like violence and poverty.

As11: Where there is controversy in social issues, this may arise (or does arise) because people have a specific worldview or life view. Philosophy is able to isolate their assumptions and see what traditions or thought systems these assumptions are embedded in.

Some respondents made the point in the context of technological innovation. Here are some examples from North Africa, the US, Japan and China:

ME4: We need the humanities to think about the challenges of the new informational age. 
NA6: The standard humanities defence: we're the field that studies history and language and then integrates that with ethical concern and inquiry. [My University] now has [an] initiative that studies tech and society, for example. You need a human perspective around scientific innovations and their applications.

As4: Natural sciences create technologies and social sciences propose various policies, but it is only humanities who can tell us how they can be used wisely.

As16: Philosophy helps us foresee the impact of new technologies (or gives us the tools to do so).

\section{Challenging social norms}

Humanities research can often be the source of challenges to widely accepted social values and traditions. In this way it may actually be in tension with social cohesion. This role overlaps with critical thinking, being a specific instance of it, so we shall have more to say below. But for the moment, here is one of our interviewees testifying to the critical value of the humanities in a social context:

As2: I would just say that it is only in the humanities and social sciences that we still produce a 'critical discourse'. Science, technology and even economics have stopped performing that function. The curricula in these areas have no element of criticism per se, making it difficult for them to contribute to the formation of critical citizenship. It has proved more than once in the course of the last century that pure science and economics have failed to produce an understanding of the symbolic life that makes us social and therefore human.

This point was also stressed at our Latin American workshop.

\section{Institution building}

Finally, it is worth recording three interview responses (from India, Lebanon and Russia) that linked the humanities to the creation and nurturing of strong institutions:

ME3: The humanities are essential for building strong institutions.

As6: You need some insight into the relation between the subject and the world in order to make institutions stronger.

R1: The humanities help people to be aware of how they think and why they do certain things. It is like cement that holds together 
social practices and institutions. The humanities enable social institutions to evolve and become better. That is why having the humanities in society is the same thing as enabling society to continue to exist.

\section{Heritage, culture, memory}

\section{Preserving cultural memory and identity}

Preserving and promoting cultural heritage has long been viewed as a function of the humanities, as is obvious not only in the case of history and language, but also literature, the arts, philosophy and religion. The value of the humanities here could lie not only in preserving cultural identity, but also in rediscovering it. As seen in China with the revival of interest in Confucius as a reaction to the Cultural Revolution of the 1970s, which attempted to root out Confucianist traditions. Other examples can be found in the wake of major political transformations where there is an emphasis on nation building and national histories, as discussed in our Russia workshop, when the humanities acted as an important tool to define nations in the post-Soviet republics. The same emphasis on nation building also applies within Russia, and the government actively promotes an interest in Russian history to this end. ${ }^{11}$

As an extension of this approach, some also refer to the way nations might promote their heritage abroad, perhaps as a way of developing 'soft power'. A current example also concerns China, and the initiative to establish Confucius Institutes around the world, not just to promote the learning of Chinese, but also a wider appreciation of Chinese culture. Again, such initiatives provide an obvious role for humanities research.

Aside from the use of history, literature, philosophy and religion, the preservation of a linguistic culture is yet another category to be noted. This is an acute issue where minority languages are concerned, though this is not the only context. With the growing dominance of English, governments of non-Anglophone countries have felt the need for a language policy, and here the expertise of humanities researchers is obviously relevant.

Here are some interview responses, mainly from Europe, that highlight cultural heritage:

Af1: The humanities are our heritage. We must sustain it. We must preserve it. 
R2: Humanities are crucial for upbringing of a new generation as they provide those who participate in the process (parents, children, teachers, educational structures, etc) with the notion of culture, tradition and cultural transmission.

R3: One of the few absolute treasures of Russia is its literature, replacing her history, philosophy, and religion. Until the end of the 20th century (before the era of postmodernism) literature was the distinguishing feature of the national culture.... I am convinced that Russian culture can be understood adequately with help of its literature.

E8: We're the keepers of memory and have to pass this on to our students.

E10: Humanities give a sense of belonging. Without humanities, identities (ethnic, national, cultural, etc.) could not exist.

\section{Nationalism and essentialism}

The idea of preserving or rediscovering a heritage raises a number of problems. It can lead to extremely superficial research (e.g. the promotion of 'cosmetic Confucianism'), and nationalist agendas may lead to downright falsification of the past. More fundamentally, these approaches may be faulted for assuming the existence of a fixed national culture waiting to be preserved. Typically, objections to 'cultural essentialism' will come from within academia, so it is easy to see humanities scholars coming into conflict with the state over the issue. Clear examples can be found when a state wishes to set the national history curriculum for schools and tries to enlist the support of humanities researchers. This is becoming an acute problem in Russia, as discussed in the HWR workshop, but also mentioned by one respondent:

R6: Russian higher education is suffering from the ministry's excessive control over its content. The ministry or its affiliated agencies check course syllabuses and programs, establishing, e.g., syllabus writing guidelines. This has a double effect, stifling faculty's creativity (since they have to submit the documents in a single standard form) and creating an opportunity for ideological control in the humanities. The latter is clearly observed in such initiatives as a single normative history textbook for secondary schools or government control over History Society and other fledgling professional associations. The case of a researcher from Murmansk 
(and numerous scientists) prosecuted for allegedly divulging classified information to foreign collaborators came as a warning for many in the field of history of Russia.

This phenomenon can also be found elsewhere, in much milder forms, perhaps. In the UK, for instance, prominent academics and others spoke out against what they saw as a naïvely nationalist curriculum being proposed by the then Education Secretary. ${ }^{12}$

\section{Confronting and coping with the past}

All this points to another function for the humanities in relation to cultural heritage, that of challenging conceptions about national identity. Indeed, by rejecting myths about the past, good humanities research might actually fend off bad national ideology. But this is just part of a broader function for humanities research - particularly in history - of confronting difficult aspects of a nation's past, which at the most extreme might concern acts of genocide. In turn, confronting the past in this way can lead to the process of coping with the past and reconciliation. Again, this is a context in which humanities research is essential.

Here are three interview responses that raise some of these issues, from Turkey, Russia and Mozambique:

ME2: We have an ongoing and deep conflict with national history as perceived by the state, the government, and the public opinion in general.... In general, the political establishment has a very negative view of the humanities, which is shared by the great majority of the population: unless they espouse nationalist historiography, scholars are seen as snobbish intellectuals or even traitors, kowtowing to Western demands. But there's no outright censorship.

R4: The state has a more significant ideological influence on research of the history of Russia. A major concern for the Russian scientific community has caused a politically motivated prosecution of Arkhangelsk historian Mikhail Suprun, who the court found guilty of 'illegal gathering of information about the private life'. He studied the biographies of German prisoners of war and ethnic Germans, Soviet citizens interned in the post-war years in the Arkhangelsk region.

Af8: I'm working with questions related to memory that are a deconstruction of the official history... 


\section{Understanding and negotiating other cultures}

In addition to understanding, promoting or challenging one's own culture, humanities research can enable one to understand other cultures. Understanding one's trading partners is increasingly important in an era of globalisation. The same applies in the area of security (as in US attempts to understand the Muslim world). ${ }^{13}$ What is important to note is that governments understand the need to research deeply into the histories of countries that are of economic or political concern to them. Perhaps an extreme example is the way new programmes are being established in China for the study of Greek and Roman classics, as a step towards greater understanding of the West.

\section{Overlaps}

Cultural heritage and social value clearly overlap in important ways. Understanding and promoting national heritage may provide social benefits, in particular by creating more social cohesion, ${ }^{14}$ though confronting it may of course reduce cohesion. Perhaps the cultural value of the humanities might be seen as a species of social value, but it seems legitimate to keep them apart, as made clear by our Russia workshop. Much of what we have discussed above would be more appropriately called political than social, for instance creating cohesion by promoting national history is very different from doing so by developing skills of communication and empathy.

\section{The economic value of the humanities}

\section{Analysis}

Humanities research may have economic value in issues of welfare, poverty, distribution of income, employment and business activity. For instance, businesses need to understand the cultures in which they operate, and this involves the use of historical, cultural and media research. Also, the use of language is essential to business, so both literature and linguistics are important. More specifically, the humanities contribute crucially to particular kinds of industry. They are responsible for productive output in the creative industries, like theatre, film and TV, all of which may be informed and enhanced by humanities research. The tourist industry depends in part on museums and other heritage institutions. In addition, there is direct economic value in popular books on history and literature, not to mention TV documentaries. 
Employment of graduates is an important issue in discussions about education in the humanities and liberal arts. The claim is that humanities disciplines prepare students for the world of work, whatever that may turn out to be. For instance, they teach students how to scan large bodies of text and information to detect patterns; how to use language to persuade; how to evaluate and construct arguments. There are, of course, difficulties in measuring the economic impact of the humanities and these are discussed in Chapter 5.

A few of our interviewees took up the economic argument:

E6: I would try to persuade the audience that people with degrees from the humanities have acquired (unique?) transferable skills that may be very useful in a much wider context than in professions where such degrees are directly relevant. In the humanities we study and interpret human behaviour as manifested by singular events - historical battles, works of art, all kinds of texts, etc. - and try to integrate them into larger patterns in order to understand them as well as possible. This is very different from what one does in the sciences, where the aim is to establish generalisations that, without exception, hold over a range of phenomena. Such singular events are what our lives are made up of, and the ability to interpret and understand them is therefore important at almost every workplace, of course in combination with more specialised knowledge.

As5: If you fund humanities studies, you develop analytical skills and a definite philosophy in life which help you in any profession eventually.

ME1: The more we invest in understanding human beings through SSH research, the more productive they will become.

A conspicuous appeal to the economic value of the humanities has been made by the UK Arts and Humanities Research Council, which has embraced the argument wholeheartedly. ${ }^{15}$ Strong arguments in favour of the economic value of the humanities to the creative and cultural sectors have also been made by Scandinavian and EU reports. ${ }^{16}$ However, the economic argument has provoked a backlash among other humanities scholars. A number of prominent figures in the UK have founded the Council for the Defence of British Universities (CDBU) partly to promote an understanding of the broader value of universities (not just in the humanities). ${ }^{17} \mathrm{~A}$ recent national report on humanities and social 
sciences in South Africa makes a trenchant critique of those who appeal to economic value, certainly in any narrow sense. ${ }^{18}$ In the US, commentators such as Stanley Fish and Martha Nussbaum are also well-known critics of the economic approach. ${ }^{19}$

\section{Contribution to other disciplines}

Several humanities disciplines contribute significantly to the social and natural sciences. Regardless of whatever claims are made about the value of humanities research in general, this indirect utility has been promoted by some to demonstrate the value of the humanities.

\section{Humanities and the natural and social sciences}

A simple list of humanities contributions to interdisciplinary collaboration may demonstrate this point:

- Archaeology, more than any other humanities discipline, benefits from the natural sciences (and their associated technology). But, increasingly in the field of environmental and climate science, the influence may be working the other way around. Archaeological research is becoming a more important source of evidence in these fields. ${ }^{20}$

- History is closely intertwined with the social sciences, all of which include a historical dimension or subdivision, whether political, legal, social or economic. Indeed, the fact that history so obviously contributes to the social sciences says something about the arbitrariness of the distinction between humanities and social sciences. Also, history is becoming increasingly important in the understanding of environmental change. This is part of a wider trend, the 'historical turn', where more and more academic disciplines are embracing an interest in historical perspectives. Historical research over long time-periods can bring a new perspective to the social sciences. For example, it has been shown that over time the world has witnessed a substantial decline in violent interpersonal conflicts. For instance, in Europe over the last three or four centuries there has been a substantial drop in homicide rates. ${ }^{21}$ Furthermore, it seems clear that there is a close and sustained correlation between manslaughter and alcohol consumption.

- Linguistics clearly influences the fields of psychology and sociology through social linguistics and psycholinguistics. It is also relevant to computer science. 
- In philosophy, striking examples are the use of logic in computing and, from the 'hard end' of philosophy, the influence of decision theory in economics. The different branches of philosophy of sciencephysics, mathematics, and biology - can also, in principle, contribute to the relevant areas. Philosophers in the 'continental' tradition, e.g. Foucault, have been highly influential in the social sciences; political philosophers (from both the continental and Anglo-American traditions) have also influenced sociology and economics. The dividing line between political philosophy and political science is obviously porous.

- Research in the arts (literature, visual arts and music) also impacts upon the natural and social sciences. Recent developments in musicology provide some good case studies because of the link with psychology and brain science. ${ }^{22}$ Work done by art departments is contributing to computer science as visualisation is becoming the way of understanding complex data; graphics is also becoming an interpretative tool (cf. 'the iconosphere'). Yet another example would be the contribution of literary studies to sociology, for instance in the area of youth culture.

\section{Humanities and the professional schools}

One could also claim that the three areas of international relations, law and management are beneficiaries of humanities research. These areas are interdisciplinary by nature and there is an increasing recognition that both humanities and social sciences have a vital contribution to make.

The fact that the humanities do feed into other disciplines was mentioned by our respondents:

As16: [Philosophy is] also useful for other disciplines, offering helpful weapons to analyse the basic assumptions of their theories that might otherwise pass unnoticed within their own approaches.

Af3: Humanities research is the basis on which all other knowledge is developed, communicated and translated into practical human development.... If you do not understand human beings, how can you understand any knowledge that these human beings seek to generate, communicate and apply?

Af7: Research in the natural and other social sciences may need the intervention of humanities research to be meaningful and turned 
into user-friendly products. Thus, humanities research contributes to the work of other academic disciplines.

However, this value was only occasionally mentioned, and then only in very general terms. Two exceptions come from US respondents, who answered the question about emerging research themes as follows:

NA11: There is a lot of new interesting stuff at the border between music and sound. Reconceptualising music as 'sound', thinking about music in a broader way than has been thought before. Also, in connection with visual studies, new media (there's a New Media Center here), visual studies, sound and music and culture, which would also include literature, history and anthropology. A lot is going on in those focus points. Some of it overlaps with people doing computer and cognitive science. So, along with that, I'm sure you've heard of the emerging relationship between cognitive science and the humanities. We're starting to do that here, and that means talking to people ranging from hard neuroscience, to history of science, literature, art history or history.

NA7: Neuroscience, for example, is at the cutting edge of contemporary understanding of the diseases that plague societies with increasingly ageing populations. The genomic and proteomic levels of analysis of that become so abstract that they require philosophers of mind to participate in it. And they're actually looking for people in philosophy - not really in psychology, because that's too clinical, it's not abstract enough - but they are looking for highly theoretical humanist scholarship to participate in what they're engaging in. It's a meeting point of science and art, where the difference between the two becomes extremely blurred. I think whether this becomes a larger trend is dependent upon whether people in the humanities want to participate in it.

The last extract raises an important question. Even if the humanities have a proven track record of contributing to other disciplines, and even if there is the potential for much more to be done, is all this sufficiently recognised? Do disciplinary and other institutional divides inhibit important contributions from being made? These divides take different forms: non-humanities disciplines may be reluctant to admit the influence of the humanities and may set up barriers to dialogue; humanities scholars may help to increase a sense of cultural divide between 
themselves and non-humanities scholars; university structures may impede effective communication; and publishers may be reluctant to venture into the terrain. These issues will be taken up in Chapter 6 in our discussion of interdisciplinary research.

\section{Innovation}

Several sources in a wide range of countries make a strong link between innovation and the humanities: national reports, ${ }^{23}$ blogs, ${ }^{24}$ media articles $^{25}$ and a number of our interviews. In the UK, the AHRC (Arts and Humanities Research Council) worked with NESTA (National Endowment for Science, Technology and the Arts) to produce a report entitled Arts and Humanities Research and Innovation. From the first page the authors discuss 'the distinctive contributions of arts and humanities knowledge':

The arts and humanities cover a very wide range of research disciplines, including archaeology, English literature, history, music and philosophy. They contribute to a constantly growing body of knowledge on human experience, agency, identity and expression, as constructed through language, literature, artefacts and performance. This knowledge nourishes the UK's cultural existence, and inspires creative behaviour, as well as innovative goods and services. The arts and humanities have a particularly strong affiliation with the creative industries. There is growing evidence that this research helps to fuel those industries...

The link between the humanities and innovation shot to the headlines with a famous interview by Steve Jobs of Apple. Talking in the context of product innovation, Jobs said: 'the reason that Apple is able to create products like iPad is because we always try to be at the intersection of technology and liberal arts, to be able to get the best of both.' We also found the link to innovation had taken root in Russia. Participants at the HWR workshop referred to the interest in Richard Florida's concept of the Creative Class, especially in the context of urban planning, where the arts and humanities are playing an important role.

Of course, one can question whether innovation is a distinctive feature of the humanities as opposed to other disciplines, but it is no less significant in the humanities than elsewhere. At any rate, those who advocate innovation as a value typically see the humanities as promoting 
innovation in a way that complements the sciences and cannot be replaced by them. This is the point made by Jobs. And in a companion AHRC report to the one just quoted, we found the following claim: ${ }^{26}$

Arts and humanities knowledge tends to be more particularistic, more tacit and less easy to communicate formally. This has implications for how this knowledge is created and shared with others. Yet, because they are less amenable to codification, the arts and humanities are better placed to disrupt and challenge standardised practices and conventional wisdoms... The arts and humanities add to the overall diversification of knowledge creation. They offer distinctive approaches to the understanding of human experience and activity. If innovation is to thrive, it must exploit the knowledge from the entire spectrum of an integrated research base.

We have already mentioned the fact that the different values of the humanities can overlap. It is particularly important to stress this in the context of innovation. For instance, when commentators talk of the humanities promoting innovation, they might well be using this as a way of talking up their economic value as in, the humanities help promote economic value by providing innovative ideas and models to business. In social policy, the humanities may lead policy makers to consider proposals that would otherwise not have occurred to them, to break out of old habits of thinking. ${ }^{27}$ In the case of cultural heritage, we have already mentioned the way in which the humanities can serve to question and revise preconceived views (or even myths) about national memory. This is yet another form of innovation. In current European Union policy thinking a strong case is often made for the necessity of nurturing social innovation alongside technological innovation and, as we shall see in Chapter 8 , this is a point that is often picked up by humanities advocates, who argue that social innovation may be nurtured by research into human motivations, behaviour and entrepreneurship.

On the other hand, many humanist scholars mistrust appeals to innovation as a 'buzzword'. They may claim that innovation is not an end in itself; that not all innovation is good (e.g. in the arena of cultural heritage, governments can misuse the humanities in order to invent nationalist identities).

Looking at our interview responses, it is interesting that few people mentioned innovation unprompted. Perhaps the most articulate 
expression of the role of innovation was this one, explaining the role of humanities as a vital part of a knowledge ecosystem:

NA6: Our society, especially in the recession era and era of privatisation, is fixated on market value. They think that the straight path to market growth is to put all your money in the STEM (science, technology, engineering, and mathematics) fields. What's not considered in that view is where ideas and innovations actually come from, and what the best system is for producing that. I'm a believer in the 'rich ecology' thesis. You don't get great discoveries and inventions by locking a thousand engineers in a room. You need the entire pyramid of engineers and artists and humanists with everyone sharing each others' points of view and ideas. You need a jungle.

\section{Critical thinking}

This move, the intrinsic questioning purpose of the Humanities, was summonsed both as a means of overthrowing dominant understandings but also of advancing the Enlightenment belief that questioning [sc. and] knowledge are one and the same thing. This tradition of critique appears in almost every discipline in the Humanities-its purpose is (as the philosopher Walter Benjamin proclaimed) 'to brush against the grain' of established understandings.

At its heart lies the genius of critical thought: the technique of asking deep-seated questions with the aim of gaining profound insights into the multiple challenges that face the human condition. (South Africa, Consensus Study, p. 29)

The claim that the humanities promote critical thinking is commonly made. It is particularly prominent in discussions of the value of a humanities education. In our context of humanities research, the point would be that research in humanities epitomises the use of critical thinking, and researchers pass on such virtues to their students. ${ }^{28}$ But the same type of argument can be used beyond the teaching context; books, articles and media presentations might all be thought to promote critical thinking among the wider public.

The value of critical thinking found some robust advocates among our interviewees, for instance:

NA5: Skills and sensitivities involved in learning how to think critically about the world around you are the skills and sensitivities 
that succeed across the board, whether you work in medical imaging or are poet laureate. Critical thinking is part of being human. Right now, we have a lost generation of people who really will believe anything, and that's a real educational failure. We can turn it around, but it's going to take some work.

It is not difficult to be critical of the critical thinking argument. Why, it has to be asked, is this an argument for the humanities rather than any other academic subject? Surely any discipline depends on critical thinking? Progress is made when one researcher takes on the conclusions of another and subjects them to close and critical scrutiny. It seems odd to claim this as the preserve of the humanities. ${ }^{29}$

Some may still contend that, although all disciplines thrive on critical thinking, the humanities epitomise it. This touches upon the nature of the humanities, the topic of the next chapter. Consider the following extract from one of our interviews on the question about the nature of humanities research:

As3: [Please give up to three examples of things that, due to humanities research, we know today that we did not know before, either in your own field or in the humanities in general.] I do think that this runs counter to our sense of the humanities as a dynamic discipline, and we should refuse to answer such queries because it puts the humanities in competition with, and defensive about, the knowledge that is generated by the sciences. Of course, we know much that we did not know before because of humanities research, but the most important lesson we have from the humanities is that we can still keep thinking about what we know, and see if we can unknow it, unravel it in some way, or build upon it. Do you think it is appropriate to describe the results of humanities research as 'findings'? Not if the findings are to be taken as the final word of wisdom. All findings in the humanities are provisional and subject to questioning and clarification and change and modification and dialogue and conversation.

This response seems to indicate that the end goal of research is the process of critical thinking itself. If so, it would be appropriate to single out the humanities in this way. But this comes at a price, namely that of conceding that, while the sciences do advance by way of finding answers to specific questions, the humanities do not.

Finally, a point of clarification, critical thinking is not the same as innovation. Both seem to have something in common since they might 
start from a widely accepted mode of thinking, which they then seek to change. But critical thinking is about analysis; innovation typically involves the imagination. Indeed, the creativity required by good innovation may even be stymied by too much analysis or critical thinking. This was a point made quite forcefully in our Russia workshop, as both critical thinking and innovation turned out to be important values for the participants. We realise, however, that not everyone will agree; some still hold that the two values go hand in hand. One of our respondents made exactly this point:

LA2: The main thrust of the humanities is to foster critical thinking. We need to return to the Socratic maxim, 'the unexamined life is not worth living'. If we produce citizens unable to have their own ideas, they won't be innovative and creative. I was recently talking to a Chinese scholar who made exactly this point about Chinese society; however much scientific research they do, they still need to develop creativity and innovation. In fact, this point was made in China decades ago in the 1950s.

\section{Personal and spiritual development}

Many humanities disciplines study religious and spiritual traditions through their histories and their texts. One way of doing this is selfconsciously 'clinical' and detached, for instance when scholars seek to understand such material 'from the outside'. But at our East Asia workshop, participants stressed the importance, especially in that region, of studying texts and traditions in a more 'devotional' way. That is, they might study them as a means to their own spiritual fulfilment (or, more broadly, their own personal development) and that of their students and readers. Both Buddhism and Confuciansim are commonly studied in this way by scholars in the Far East.

The idea is not alien elsewhere. Values-based universities in Africa and the US, especially those associated with a religious tradition, will typically approach many humanities disciplines in the same way. Nor is the idea necessarily religious. The study of the humanities and liberal arts explicitly for personal growth and development has been revived and advanced in the US quite recently by Anthony Kronman, interestingly enough, a Yale law professor. ${ }^{30}$ A number of our respondents saw the value of the humanities in this way, notably in Russia and Asia: 
R3: The value of the humanities is in fact that they provide tools with which a person becomes aware and realises [himself or herself] in the world.

R6: This [sc. the 'alternative academia' of biography and non-fiction authors, bloggers, museum curators, etc.] is all part of the growing demand for human self-realisation and betterment. It cannot proceed without knowledge of the past and criticism of the present.

NA13: Humanities research is about values, the meaning of existence, and of our life. Nobody can ignore this, even though most people might rarely think about this in their daily life. It is like the air, for example, or breathing, which we almost never think about in our daily life, unless there is a problem such as air pollution, or asthma, and then one suddenly realises that breathing is the fundamental activity of any being's state of being alive. Like the nutrition that one consumes every day, education of humanities offers individuals the necessary nutrition for existence. Deficiency of a specific nutrition in our body is not always visible and noticeable unless one gets sick, but if [you] wait until the illness occurs, cure might not be possible. I believe humanities research and humanities education function [in a] similar way.

As7: In the rapid development of high meaning in Asia, the first thing is of paramount importance. East Asia is all about traditions, Confucianism and all kinds of profound teachings. These things, I feel our 21st Century people are starved of and are dying for. I am a Buddhist myself...

As8: It helps people to leave a spiritual and enriched life, helps them have a rested mind and an active imagination.

\section{Aesthetic appreciation}

In music, literature and the arts generally, humanities research provides new insights to promote and deepen the appreciation of artistic beauty. Aside from the obvious ways in which humanities scholars may perform this function through undergraduate education, examples could include art historians writing material for exhibitions, and musicologists or drama scholars writing programme notes. All of these might also broadcast on radio or TV and write popular books. Literary scholars 
can communicate insights from their research through similar media, as well as book reviews.

That the humanities have such a role may seem obvious, but it turns out to be a disputed area. Academic research in literary criticism, art history and music has certainly had an aesthetic function in the past. Nowadays, there is no shortage of critics outside academia, writing and talking in the media, who aim to guide the general public in its appreciation of different kinds of artwork. But is this something modern-day academics do in the humanities? In the case of literature, it may actually be controversial to attribute such a role to researchers, perhaps because of trends such as postmodernism or, more generally, the 'democratisation' of public life, and hence the demise of academic expertise in matters of aesthetic appreciation. ${ }^{31}$

It was notable that very few of our respondents mentioned aesthetic appreciation as a value of the humanities. Here are two exceptions, both from North America:

NA11: I would remind [an impatient and potentially hostile audience] first, that the way they live their lives and the pleasure they get from the world, some high percentage of that comes from their education in the humanities. Learning how to distinguish between good [and bad] forms of communication..., between canned and serious things, between superficial things and profound things. And this doesn't just go for aesthetic experience, but just being an intelligent consumer of media, politics, business and sciences. Again, I know this sounds old-fashioned but it helps people think broadly and deeply with discrimination. If they don't care about that, then there's not really much to say. You can't convince them.

NA14: I'd prioritise aesthetic appreciation, i.e. the way research can make possible new and sophisticated forms of aesthetic pleasure. This is bound up with the way it shows how aesthetic pleasure has changed over time.

But note that in the first of these quotes aesthetic value is mentioned only briefly and is considered 'old-fashioned'.

\section{A distributional survey of the interview responses}

So far, we have been using the interview results alongside other sources to help characterise the different values of humanities research. In this 
section we examine the interviews on their own. First, we shall see how, according to these interviews, support for the different values is distributed around the world. In the final section (Strategies for justification), we look at the ways in which our respondents reflected on the idea of justifying the humanities.

Responses to the original question on reasons to fund the humanities varied widely. One point of difference was the level of generality. Some were broad-brush, others gave specific examples to illustrate the value of humanities research. But it is fair to say that in each region almost all the values we have discussed were mentioned at least once. As regards overall patterns, we can mention two: (i) one positive, a significant proportion of our respondents mentioned the social value; (ii) the other negative, very few, in answer to this question at least, mentioned economic value.

(i) Overall we found that most respondents made some sort of reference to society or the social, or at least a reference to our collective life as human beings, or to collective decision-making (e.g. about technological innovation). Europeans seemed less inclined than others to mention societal value, while more than two thirds of respondents from other regions mentioned social value. On the other hand, Europeans tended to mention cultural heritage more often than others.

(ii) Only a handful of respondents mentioned the economic value of the humanities. The small number of these references is striking, given the way the original question was set. It challenged respondents to think of themselves defending the humanities to a hostile audience. This ought to have invited them to make use of whatever arguments might resonate with their critics. Yet very few took up the opportunity to mention economic value. Perhaps this reflects something we mentioned earlier, that the economic argument is viewed with suspicion in academic circles. Those who did mention it referred to it in somewhat deflationary terms.

It is particularly interesting to reflect on this result in the US context. There, public pronouncements about the value of the humanities, whether from within academia or without, often focus on the employability of humanities graduates. Critics complain that humanities disciplines are irrelevant to the workplace and try to promote STEM subjects instead. Academics, worried that parents of students and potential students will be persuaded by this, try to fight a rearguard action. So it is 
interesting that, with two exceptions, our group of interviewees steered away from the topic, despite the terms of the question.

As indicated above, after conducting 45 interviews, we added a component to the questionnaire, which gauged respondents' reactions to the values we have been discussing in this chapter. We asked them which values they considered most important, and which their society did. We had 44 responses from Africa, Australia, Latin America, the MENA region, Russia and Asia.

The responses to the added question showed a disparity between the interviewees' own attitudes and those they felt prevailed in their own country. Although intrinsic value is popular among the respondents themselves, far fewer thought that it would gain any purchase in society at large. It is also noteworthy that, while the interviewees tended to believe in the social value of the humanities for policy making, they are less sanguine about whether their societies would agree. The same applies to the responses regarding critical thinking and innovation. On the other hand, there is a relative alignment between attitudes on cultural heritage. Yet again, we see that economic value is not something many humanities scholars espouse, though more think that it is something society expects of them. There is clearly more work to be done in future studies on the preferences of humanists.

\section{Strategies for justification}

Finally, we turn to a meta-issue arising from the interviews. Because of the way the original question was framed, some respondents took it as a cue to discuss the very idea of justifying the humanities. Occasionally, respondents counselled against arguing with a hostile audience at all; or they warned about the dangers of responding to critics operating within narrow, short-term paradigms.

If these responses were right, perhaps the entire thrust of this chapter might be considered misconceived. Haven't we been talking all along about justification, simply assuming that it is something worth doing? But this would be a mistake, because there is an important distinction between justifying and articulating the value of the humanities. By articulating, we mean explaining and differentiating the different values or benefits humanities research is thought to have. This is, in fact, all we have been doing for most of this chapter. Justifying the humanities is subtly different as it involves defending the humanities in the face of a challenge. Unlike articulation, justification is self-consciously rhetorical. There are potentially hostile audiences to 
consider, for instance: politicians nervous of their budgets; people who consider STEM subjects worth funding but struggle to see the point of the humanities.

Now one could argue, like the respondents above, that one simply should not engage in this kind of defensive manoeuvre at all. But that does not mean that one should not engage in the distinct project of articulation. It is important, and interesting for other reasons, to be aware of the different ways in which the humanities contribute to our lives, individually and collectively. Besides, we do not agree that all attempts at justification are misplaced. We need to give some account of ourselves to those who fund us and it would be wholly impractical to disengage altogether (even if a few critics are beyond the pale). It is also useful for us to challenge ourselves about our own motivations and values, irrespective of what others may think. So, let us turn to another group of respondents who agreed that we should engage with impatient and hostile audiences, but held that there are better and worse ways of doing so. The idea of tapping into a pre-existent or at least implicit interest was one favoured approach. For instance, one European respondent described how a historian might ask people about their family, such as their grandparents' childhood. This starts a conversation about what it was like in that period. Once such interest has been generated, some kind of dialogue becomes possible, and the historian can then introduce what they know about the past. In the US seven respondents also offered some constructive thoughts about how to open up people's minds to the issue. One thought that the key was to find a topic, probably local in nature, in which an interlocutor would already be interested, for instance a poet from their own state. The strategy would then be to show how academic research could affect the way we think of this author and, by extension, the region from which they came. Others went further and stated that the humanities already play a significant role in people's lives. Both these responses suggest that interest in the humanities may lie just beneath the surface, even in an impatient interlocutor; they merely need 'reminding'. Other respondents went a step further and insisted that people outside academia are already interested in the humanities. 'The fact is that we engage in humanistic thinking whether we know we do or not - when we talk about drones or stem cell research.' Another thought that politicians' critiques of the humanities fail to recognise the crucial importance that the humanities (e.g. literature) play in so many people's lives.

If these optimists are right, we need to be able to exploit public interest in the humanities, be it only latent. This requires effective 
communication. But, according to two US respondents, humanities scholars may sometimes be their own worst enemy:

NA7: I think the humanities are partially to blame. We've spent a decade talking to ourselves in an esoteric language that nobody else understands or thinks is relevant. I'm not saying that the humanities need to sacrifice complexity in order to communicate, but nevertheless the humanities need to become more self-reflective themselves. What is the culturally critical function of the intellectual interrogations that they are engaged in? The humanities must find a way to limit [their] esotericism, without compromising the complexity of [their] interrogations.

NA10: There's a lot of appreciation for the humanities. We founded a programme called the free minds programme, a one-year humanities course for adults, most of whom are low-income, ethnic minorities, and never went to college. They value the humanities. They value being able to think through issues and to have exposure to that kind of cultural capital. I think it's a matter of speaking beyond the academy, of speaking in a non-jargony language, of speaking about issues that people really care about and about the meaning of human life. Much humanities scholarship has moved away from the issues that really motivate people. So I think it's important to stay centred in those issues that people are facing every day.

These comments act as a salutary reminder when it comes to advocacy. If there is a problem of hostility and impatience in public attitudes, part of the solution may lie in our own hands.

\section{Conclusions}

This has been a wide-ranging survey, though in many ways we have barely been able to scratch the surface. But, by pulling some strands together, we can make the following points:

1. Almost all the values we listed at the beginning find supporters right across the world. The social value of the humanities is particularly popular. If scholars wish to find a single value to unite rather than divide them, they should persist in articulating it. It makes the humanities not only noble, but also useful. 
2. Several respondents mentioned the intrinsic value of the humanities. We identified a hybrid form of this approach, where the curiositybased pursuit of knowledge can actually lead to significant instrumental benefits. This hybrid justification could be an essential part of the rhetoric, pointing to the long-term societal value of being indifferent to such value in the short-term.

3. The role of the humanities regarding cultural heritage is also very important, but it needs to be handled with care. As has long been the case, political pressures can lead to abuse of academic standards in this domain.

4. The economic value of the humanities receives only lukewarm support. In the main, our respondents tended to avoid it. So justificatory appeals to economics are likely to divide humanities advocates from one another. Nonetheless, if the evidence can be found to support the argument, there is no reason why it should not be articulated. Its opponents need to explain why, if it is rooted in fact, it should not be deployed as one argument among others.

5. Humanities scholars should always be on the alert not to become their own worst enemy. The merits of clear and accessible communication (without losing nuance and sophistication) should always be borne in mind.

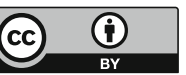

Except where otherwise noted, this work is licensed under a Creative Commons Attribution 3.0 Unported License. To view a copy of this license, visit http://creativecommons.org/licenses/by/3.0/ 